\title{
EDUCAÇÃO CORPORATIVA E INCLUSÃO DIGITAL NO CENÁRIO DA ADMINISTRAÇÃO PÚBLICA
}

\author{
EDUCACIÓN CORPORATIVA E INCLUSIÓN DIGITAL EN EL ESCENARIO DE \\ LA ADMINISTRACIÓN PÚBLICA
}

\section{CORPORATE EDUCATION AND DIGITAL INCLUSION IN THE PUBLIC ADMINISTRATION SCENARIO}

\author{
Elieti Cadamuro GUEDES ${ }^{1}$ \\ Julio Cesar TOMASI CRUZ ${ }^{2}$
}

RESUMO: O presente ensaio tem como ideia central a Educação Corporativa para a promoção da inclusão digital no cenário da Administração Pública. A educação corporativa nasce como aperfeiçoamento do treinamento tradicional, visando a formação continuada do corpo de colaboradores da empresa. A inclusão digital e as tecnologias estão intimamente relacionadas, sendo importantes tanto para a organização como para o colaborador. A metodologia adota pelos autores foi de pesquisa bibliográfica. Embora o setor público disponha de diversas tecnologias, ainda muitos colaboradores não sabem utilizá-la, de forma que este setor possui muito a desenvolver com relação à educação corporativa, tecnologias de informação e comunicação, e inclusão digital propriamente dita.

PALAVRAS-CHAVE: Educação Corporativa. Inclusão digital. TIC. Administração pública.

RESUMEN: El presente artículo tiene como idea central la Educación Corporativa para la promoción de la inclusión digital en el escenario de la Administración Pública. La educación corporativa nace como perfeccionamiento del entrenamiento tradicional, visando la formación continuada del cuerpo de colaboradores de la empresa. La inclusión digital y las tecnologías están íntimamente relacionadas, siendo importantes tanto para la organización y para el colaborador. La metodología adoptada por los autores fue de investigación bibliográfica. Aunque el sector público dispone de diversas tecnologías, aún muchos colaboradores no saben utilizarla, de forma que este sector tiene mucho que desarrollar con relación a la educación corporativa, tecnologías de información y comunicación, e inclusión digital propiamente dicha.

\footnotetext{
${ }^{1}$ Universidade Estadual Paulista (UNESP), Bauru - SP - Brasil. Tecnólogo em Processamento de Dados Universidade de Bauru (1988). Analista Tributário da Receita Federal do Brasil - Carreira Tributária e Aduaneira da Receita Federal do Brasil, Analista no Setor de Fiscalização, Representante da Educação Fiscal na Delegacia, Representante do NAF (Núcleo de Apoio Contábil e Fiscal) na Delegacia da Receita Federal do Brasil em Bauru. ORCID: <https://orcid.org/0000-0002-4815-9999>. E-mail: elietiguedes@yahoo.com.br

${ }^{2}$ Faculdade de Tecnologia de Praia Grande (FATEC-PG), Praia Grande - SP - Brasil. Graduando em Tecnologia em Gestão Empresarial. Estagiário Administrativo ETEC - Praia Grande. ORCID: < https://orcid.org/0000-0001-8775-8727>.E-mail: juliotomasi@ hotmail.com
} 
PALABRAS CLAVE: Educación Corporativa. Inclusión digital. TIC. Administracion publica.

ABSTRACT: This article has as main idea the Corporate Education for the promotion of digital inclusion in the Public Administration scenario. Corporate education is born as an improvement of traditional training, aiming at the continuous training of the company's employees. Digital inclusion and technologies are closely related and important for both the organization and the collaborator. The methodology adopted by the authors was bibliographic research. Although the public sector has several technologies, many employees still do not know how to use it, so this sector has much to develop in relation to corporate education, information and communication technologies, and digital inclusion itself.

KEYWORDS: Corporate Education. Digital inclusion. ICT. Public administration.

\section{Introdução}

Pensando na formação das habilidades e competências dos funcionários, colaboradores e demais profissionais que atuam no cenário mercadológico, tanto público quanto privado, algumas empresas começaram a investir na Educação Corporativa (EC) ou na criação das Universidades Corporativas, objetivando aprimorar a formação para o desenvolvimento das habilidades e competências de seus empregados. Essa ação promove a inclusão, tanto digital quanto no mercado de trabalho, para que possam desenvolver suas atividades de maneira eficiente e eficaz.

Nesse contexto, este ensaio teórico se debruça sobre o conceito da Educação Corporativa para a promoção da inclusão digital no cenário da Administração Pública. Um dos pontos fundamentais nessa questão é que boa parte dos cursos de formação ofertados pela EC é através da Educação a Distância, para que a formação possa contribuir e promover formação com qualidade mediante as Tecnologias de Informação e Comunicação (TIC). Diante do cenário que se apresenta nessa pesquisa, pergunta-se como a Educação Corporativa pode contribuir na Administração Pública com foco no desenvolvimento das habilidades e competências para uso das TIC e a inclusão digital?

Os serviços públicos, desde os administrativos, serviços bancários e demais empresas estatais, cada vez mais estão buscando formar profissionais para que possam atuar de maneira eficiente, tanto no atendimento ao contribuinte como também na melhoria dos processos internos das instituições. Para isso, é notória a necessidade de formar profissionais para atuarem no cenário globalizado, em que as tecnologias estão 
cada vez mais presentes. Nesse sentido, é necessário Aprender a aprender - o aprendizado é constate, sendo inerente ao homem o ato de aprender constantemente; Ter Comunicação e colaboração - a comunicação deve ser eficaz; Raciocínio criativo e resolução de problemas - assertividade e pensamento lógico, dessa forma as ações se tornam diretas e eficazes; Educação tecnológica - educar para o cenário digital; Educação em negócios globais - visão sistêmica no cenário globalizado; Desenvolvimento de liderança - atitudes assertivas e colocar-se no lugar do outro; Autodesenvolvimento de carreira - buscar formação constantemente.

Sendo assim, primeiramente se faz uma abordagem teórica sobre os conceitos da Educação Corporativa, em seguida um panorama no contexto da inclusão digital e a formação do sujeito para atuar nos serviços públicos.

\section{Educação Corporativa (EC) no contexto atual: conceitos e viabilidades na formação das habilidades e competências}

Em tempos de tecnologias ubíquas, cada vez mais o fluxo de informações no mundo globalizado é crescente e realizado em tempo real. Essa questão influencia intrinsecamente na necessidade das empresas empregarem recursos no desenvolvimento de seus colaboradores. Desse modo, é essencial fornecerem uma contínua qualificação para que possam acompanhar o desenvolvimento que os setores da economia, política e sociedade em geral alcançam, pois esses cenários vêm se transformando, ambiente para o qual se torna fundamental aplicar novos conhecimentos mediante a formação necessária para os coadjuvantes sociais (EBOLI, 2012). Destarte, surge a Educação Corporativa ou Universidade Corporativa - termos equivalentes, segundo Eboli (2014, p. 16) -, que se diferencia do treinamento tradicional, isto é, a educação corporativa possui uma concepção mais ampla, dentro de uma estrutura de formação e educação, enquanto o treinamento possui um espaço delimitado - sendo aplicado de maneira específica - (MEISTER, 1999 apud RICARDO, 2012).

Como é sabido, o tema Educação Corporativa surgiu primeiro no mundo corporativo, para depois ganhar espaço no mundo acadêmico. Ainda não é um tema robusto o suficiente sob o ponto de vista conceitual, mas exuberante em termos da prática empresarial. (EBOLI, 2004, p. 1) 
A EC iniciou-se pelas empresas com o foco de promover treinamentos, mas com o passar do tempo a Educação Corporativa ganha outros olhares a partir das pesquisas acadêmicas, principalmente por estar relacionada à Educação. Eboli aponta que,

O contexto de surgimento e a dinâmica das universidades corporativas (UCs) são um tema que merece ser discutido, pois elas têm revolucionado a forma de se capacitar pessoas nas organizações, indo muito além do ambiente empresarial, na medida em que também influenciam os sistemas educacionais e a produção do conhecimento dentro da sociedade contemporânea. Deve-se salientar que programas educacionais nas empresas sempre existiram, mas normalmente eles eram restritos aos níveis gerenciais e à alta administração. Para a grande maioria dos funcionários havia programas de treinamento pontuais. O surgimento das UCs foi o grande marco da passagem do tradicional "centro de treinamento e desenvolvimento" (T\&D) para uma preocupação mais ampla e abrangente com a educação de todos os colaboradores de uma empresa, e, na prática, é com o seu advento que vem à tona a nova modalidade de educação corporativa. Assim sendo, ao longo deste capítulo, universidade corporativa e educação corporativa serão aplicados como termos equivalentes. (s/d, p. 2)

Entretanto, educar não está apenas em treinar, mas formar e mediar conteúdos para que os sujeitos possam articular e disseminar conhecimentos adquiridos diante dos conteúdos abordados nos cursos que são oferecidos pela EC. Para Eboli (2012, p. 31), os "departamentos de treinamento operavam como 'anotadores de pedidos". De certa forma, estes departamentos apenas ofereciam os treinamentos para os quais foram contratados, de modo que não possuíam foco direto nos resultados (EBOLI, 2012). O treinamento tradicional é focado apenas nos funcionários; segundo Ricardo (2012, p. 9), "os conteúdos são, na grande maioria, de consultores e professores contratados, tendo atividades pontuais, direcionados a propagar técnicas e desenvolver a qualificação dos indivíduos".

Pode-se verificar que a formação apenas para desenvolver competências não era mais suficiente, sendo imprescindível agregar habilidades na formação. Sair do treinamento para educar e formar com práticas e experiências, assim os funcionários passariam a aprender a aprender, aprender a ser, aprender a fazer e aprender a conhecer, princípios baseados na ideia de Delors, publicados em relatório da UNESCO.

Para isso se faz relevante conhecer as diferenças entre tais paradigmas, assim, o quadro 1 elucida a quebra de paradigma entre o treinamento tradicional e a aprendizagem baseada na Educação Corporativa. 
Quadro 1: Paradigma Treinamento para a Aprendizagem

\begin{tabular}{|c|c|c|}
\hline $\begin{array}{c}\text { Antigo Paradigma de } \\
\text { Treinamento }\end{array}$ & $\begin{array}{c}\text { Paradigma de Aprendizagem } \\
\text { no Século XXI }\end{array}$ \\
\hline Prédio & Local & $\begin{array}{c}\text { Aprendizagem disponível } \\
\text { sempre que solicitada }- \\
\text { em qualquer lugar, a qualquer } \\
\text { hora. }\end{array}$ \\
\hline $\begin{array}{c}\text { Atualizar qualificações } \\
\text { técnicas }\end{array}$ & Conteúdo & $\begin{array}{c}\text { Desenvolver competencias } \\
\text { básicas do ambiente de } \\
\text { Negócios. }\end{array}$ \\
\hline Aprender ouvindo & Metodologia & Aprender agindo. \\
\hline Funcionários internos & Público-alvo & $\begin{array}{c}\text { Equipe de funcionários, } \\
\text { clientes e fornecedores de } \\
\text { produtos }\end{array}$ \\
\hline $\begin{array}{c}\text { Professores/Consultores de } \\
\text { Universidades externas }\end{array}$ & Corpo docente & $\begin{array}{c}\text { Gerentes seniores internos e } \\
\text { um consórcio de } \\
\text { professores universitários e } \\
\text { consultores. }\end{array}$ \\
\hline Evento único & Frequência & $\begin{array}{c}\text { Processo contínuo de } \\
\text { aprendizagem. }\end{array}$ \\
\hline $\begin{array}{c}\text { Desenvolver o estoque de } \\
\text { qualificações do individuo }\end{array}$ & Meta & $\begin{array}{c}\text { Solucionar problemas } \\
\text { empresariais reais e melhorar } \\
\text { o desempenho no trabalho. }\end{array}$ \\
\hline
\end{tabular}

Fonte: Meister (1999, p. 22 apud Andrade, p.31) - Adaptado pelos autores.

Com isso, a EC passa a priorizar o desenvolvimento de modo amplo, com visão sistêmica, e o treinamento baseado na qualificação passa a ser incompleto para as demandas de competitividade e de acesso à informação necessárias para alcançar os mais variados conhecimentos disponíveis na atualidade, no mundo contemporâneo e competitivo. Com essa concepção,

A educação corporativa é mais do que treinamento empresarial ou qualificação de mão-de-obra. Trata-se de articular coerentemente as competências individuais e organizacionais no contexto mais amplo da empresa. Nesse sentido, práticas de educação corporativa estão intrinsecamente relacionadas ao processo de inovação nas empresas e ao aumento da competitividade de seus produtos (BRASIL, 2017).

Competências como aprender a aprender; comunicação e colaboração; desenvolvimento de liderança, são cada vez mais exigidas no mercado atual, e a partir disso é que a Educação Corporativa se destaca, com a ideia de desenvolver os stakeholders de modo geral, isto é, na EC, os disseminadores do conhecimento podem ser desde os colaboradores como consultores externos e demais protagonistas que disseminam informação e conhecimento (EBOLI, 2014; RICARDO, 2012).

A Educação Corporativa, segundo Eboli (2014, p. 14), "têm desempenhado um papel estratégico na construção da competitividade empresarial por meio do 
desenvolvimento das competências humanas de forma atrelada às competências empresariais".

É interessante destacar que a Educação Corporativa pode ser entendida como uma ferramenta capaz de mediar a disseminação da cultura e dos valores da empresa (SANTOS CRUZ et al, 2017 [online]). Ainda para os autores, a EC possui a promoção da mudança como uma característica importante, isto é, "os itens abordados e a estratégia de aplicação se caminharem em conjunto com os objetivos da empresa podem auxiliar a chegar no objetivo final desejado da corporação".

\section{Importância da Educação Corporativa no processo de Inclusão Digital}

A educação corporativa passou ao longo do tempo por vários momentos. Desde momentos de aprendizado somente teórico, momentos em sala, universidades corporativas dentro da própria empresa até o momento em que a tecnologia (TIC) começou a ser utilizada para facilitar a propagação do conhecimento (SANTOS CRUZ et al, 2017).

Cada vez mais, as tecnologias são inseridas nas vidas das pessoas, entretanto, ainda existem pessoas que possuem pouco domínio em relação a estas tecnologias, caracterizados como analfabetos digitais, e estes, segundo Brasil (2015, p. 15) "permanecem afastados de novas oportunidades de trabalho, novos conteúdos culturais, bem como de novas formas de exercer a cidadania.”. Ainda sobre o assunto podemos acrescentar:

[...] iniciativas de inclusão digital são aquelas que visam oferecer à sociedade "os conhecimentos necessários para utilizar com um mínimo de proficiência os recursos de informática e de telecomunicações existentes e dispor de acesso físico regular a esses recursos". A inclusão digital se assemelha, portanto, à ideia de alfabetização digital, numa equivalência com a perspectiva da alfabetização no processo de inclusão social, voltando o foco para aqueles que também se encontram no próprio contexto de exclusão social, acrescentando a temática da tecnologia digital no sentido de somar esforços para atenuar essa diferença (CABRAL, 2004 apud BAPTISTA, 2006).

Muitos usuários possuem resistência à aceitação da tecnologia, isto porque as ferramentas tecnológicas para algumas pessoas trazem dúvidas e incertezas sobre como utilizá-las. Marakas e Hornik (1996 apud ALBERTIN; BRAUER, 2012, p. 1373) dizem 
que: "O medo e estresse das consequências do sistema desconhecido são, segundo tais autores, os fatores causadores da resistência”.

No mundo atual, consistente da sociedade de informação, ocorrem mudanças diárias quando se pensa na tecnologia, onde, por exemplo, cursos que eram aplicados de forma presencial passam ser possíveis de serem ministrados online, dispensando um gasto considerável para as empresas. Desta forma, segundo Ricardo (2012, p. 53), 87\% das empresas adotaram a Educação a Distância. Sendo assim, é necessário que a empresa qualifique seu colaborador a utilizar as tecnologias de informação, para que o mesmo aproveite satisfatoriamente os benefícios da tecnologia e da educação corporativa.

As tecnologias impulsionam as organizações, tanto economicamente como ao oferecer vantagens competitivas, entretanto, para que esses benefícios sejam vistos pela organização, é necessário a aceitação e aplicação destas tecnologias na empresa (ALBERTIN; BRAUER, 2012)

A Educação Corporativa é desenvolvida por todos, de maneira que uns compartilham seus conhecimentos com os outros, e, desta forma, o colaborador que possuir um conhecimento maior das tecnologias implantadas na empresa, passa a ser disseminador de seus conhecimentos a outros colaboradores que possuam dificuldades com a utilização destas tecnologias.

O uso das TIC se caracteriza, ao mesmo tempo, como uma oportunidade e um risco ao equilíbrio social, pois pode conduzir tanto à redução da desigualdade de renda entre as classes e à melhoria da qualidade de vida, pela equidade de oportunidades, como à perpetuação da desigualdade, pelo surgimento de uma classe excluída digitalmente (BRASIL, 2015).

Torna-se importante o colaborador estar preparado para a era da tecnologia, bem como para a empresa é importante aliar a inclusão digital e o desenvolvimento de ações utilizando a Educação a Distância, isto porque, segundo Santos Cruz et al (2017, p. 9), o ensino a distância "é capaz de promover distribuição de conhecimento de forma rápida, permitindo que os colaboradores acessem as informações a qualquer momento que precisarem". De modo que:

A inclusão digital não deve ser encarada apenas como um canal de comunicação entre pessoas, visando a quantidade de acessos, mas sim como um instrumento de acesso a informação, produção do conhecimento e estímulo ao aprendizado através da qualidade do 
conteúdo/informação acessada, para promover a inclusão social na denominada sociedade da informação (CARNEIRO; SILVA, 2012).

\section{Educação Corporativa, Administração Pública e Tecnologias de Informação e Comunicação: da prática à realidade}

Se por um lado vivemos com a tecnologia ao nosso lado, por outro, nem todos estão prontos para utilizá-la. De acordo com Sá e Costa (2011, p. 31): “A evolução da humanidade tem-se dado num ambiente caracterizado por sucessivas e constantes mudanças, com o surgimento cada vez maior de inovações e com avanços tecnológicos que se difundem numa velocidade sempre crescente". Nesse caso:

A aplicação das TIC para uma melhor governança, a e-governança, tem então como áreas: a e-administração pública, que pressupõe melhoria dos processos governamentais e do trabalho interno do setor público com a utilização das tecnologias de informação e comunicação; e-serviços públicos, que prevê melhoria na prestação de serviços ao cidadão; e a e-democracia, que subentende maior e mais ativa participação do cidadão, possibilitada pelo uso das tecnologias de informação e comunicação no processo democrático. (CUNHA; MIRANDA, s/p, 2013)

$\mathrm{Na}$ vivência do setor público, é visível o despreparo da maioria dos colaboradores, muitos estão ali há um certo tempo fazendo seu trabalho diário, e demonstram falta de preparo adequado para desempenhar sua função, gerando um nível considerável de críticas por parte da população. “A utilização da TIC no contexto da educação corporativa desponta como essencial para que se obtenha o resultado esperado, também porque, na atualidade, elas encontram-se de várias formas, amplamente incorporadas ao ambiente de trabalho". (SÁ; COSTA, 2011, p. 33)

$\mathrm{Na}$ década de 90, o setor público inicia o processo de migrar para o mundo virtual, espaço digital para que cidadãos tenham mais acesso, mas principalmente para as empresas públicas estarem no processo de globalização e competitividade. De acordo com Cunha e Miranda (2013, s/p), "Em alguns estados, os serviços foram organizados com foco na busca do cidadão [...] e a maioria dos estados brasileiros, o governo federal, todas as capitais e muitos municípios já possuem sites de prestação de serviços".

É nítida a necessidade de desenvolvimento destes colaboradores. Por um lado, Araújo (2011, p. 71) diz que a Educação Corporativa preconiza o aprendizado de todos 
os colaboradores e não apenas os níveis gerenciais, por outro, observamos que no setor público não é o que ocorre. Retomamos Sá; Costa:

Diante das condições atuais impostas pelo mundo globalizado e digital, a educação continuada, ou educação ao longo da vida, se firma como opção única aos indivíduos que almejam ser competitivos no mercado de trabalho. Além disso, a qualificação da população é condição mínima indispensável para que as nações possam inserir-se de forma competitiva nessa globalização, o que faz com que a formação continuada seja, praticamente, um dever de Estado. Nesse panorama, a educação corporativa e a utilização das tecnologias como ferramentas de facilitação do processo ensino-aprendizagem e de inclusão digital são instrumentos que não se pode prescindir nos projetos de educação continuada. (SÁ; COSTA, 2011, p. 36)

A experiência de um estágio em uma escola pública mostrou que o desenvolvimento e aperfeiçoamento de conhecimentos ocorre em grande parte para os níveis táticos e gerenciais, deixando de lado o nível operacional. Para Schikmann, apud Andrade:

Muitas organizações públicas, as áreas de Recursos Humanos estão estruturadas de forma arcaica, bem ao estilo 'departamento de pessoal', dedicando-se a questões limitadas à folha de pagamento, aposentadoria, licenças, proposição de leis e regulamentos e algumas ações de treinamento (SCHIKMANN, 2010 apud ANDRADE, 2012).

De fato, muitas organizações públicas possuem esta estrutura. De modo geral, os colaboradores que fazem parte da equipe da área de recursos humanos da unidade apenas seguem as regras que recebem do departamento geral de recursos humanos, isto é, não possuem autonomia para desenvolver as habilidades do corpo de colaboradores, que poderiam atender lacunas encontradas no setor público, pois, para isso, dependeriam da autorização superior. Novamente fazemos referência a Sá; Costa, que consideram que:

\begin{abstract}
A educação não caminha dissociada das transformações ocorridas na sociedade em que se insere num determinado período histórico. Ao contrário, ela é resultado da visão de mundo dos grupos que a constituem. Dessa forma, é inevitável que a educação, refletindo os tempos atuais, se aproprie cada vez mais das tecnologias disponíveis, revertendo-as em benefícios a serem incorporados no processo ensinoaprendizagem. (SÁ; COSTA, 2011, p. 40)
\end{abstract}

Quando pensamos nas tecnologias da informação e comunicação, nos deparamos com o analfabetismo digital, como tratado anteriormente. De modo que se faz 
necessário, antes de tudo, o desenvolvimento digital dos colaboradores que possuam dificuldade.

Para Santos Cruz e Bizelli (2014, p. 260), “a inserção das TIC em sala de aula, por exemplo, depende de atores educadores que carreguem em seu perfil profissional habilidades que permitam trabalhar com desenvoltura nas redes de inovação”. Os autores elucidam que o responsável pela inserção das tecnologias da informação e comunicação necessita de habilidades diferenciadas, desta forma, o profissional do setor público, muitas vezes, não está preparado para a utilização destas ferramentas.

Por mais que o setor público possua cursos para seus colaboradores, conforme supracitado, estes são definidos apenas como capacitações e não como desenvolvedores de habilidades e competências, assim sendo, o setor público em sua maioria ainda foca o setor de recursos humanos como mero coadjuvante, e não como protagonista no desenvolvimento de seus colaboradores.

\section{Considerações finais}

A Educação Corporativa reinventa o treinamento tradicional muito presente nas empresas, tanto privadas como públicas, ao focar além do aprendizado para exercer a função, isto é, foca na formação continuada, no aperfeiçoamento das habilidades e competências do colaborador, e não mais só nas áreas gerenciais.

A inclusão digital pode ser entendida como uma forma de Educação Corporativa, pois a constante evolução tecnológica tem trazido à tona a classe de analfabetos digitais. Quando pensamos com o olhar da Educação Corporativa, entendemos que o aprendizado não é apenas realizado por um professor, mas sim por todos; com isso, podemos contar com o compartilhamento do conhecimento de cada indivíduo presente na organização; desta forma, esta ação, além de promover a inclusão social, também dissemina o conhecimento a todos os colaboradores.

Quando olhamos para o serviço público, temos a visão de um serviço que ainda trabalha com o treinamento na maneira antiga, focado aos superiores. Ainda que o setor público promova uma formação continuada, este ocorre sobretudo para profissionais que estão lotados em cargos de comando. Muitos dos colaboradores possuem certo grau de analfabetismo digital, sendo assim, as tecnologias que muitas vezes são empregadas no setor público para que possam facilitar o dia a dia no trabalho acabam atrapalhando a 
rotina laboral, e, desta forma, o colaborador acaba prestando um serviço que ao olhar da sociedade é ineficaz.

Visando o cenário supracitado, cada vez mais as organizações estatais buscam se renovar, e aplicar o conceito das tecnologias de informação e comunicação no ambiente de trabalho, para que possam aperfeiçoar a forma de realização das funções cotidianas não só para o colaborador, mas também para o contribuinte; entretanto, para que isto ocorra, faz-se necessário o aperfeiçoamento destes colaboradores, e, com foco nisso, as organizações buscam investir na educação a distância, a qual não exige que o colaborador se ausente de seu ambiente de trabalho.

Acreditamos que o setor público ainda tem muito a desenvolver com relação à Educação Corporativa, tecnologias de informação e comunicação e inclusão digital, focando não apenas em colaboradores que ocupem cargos de comando, mas também no restante do quadro de funcionários, e assim aplicar efetivamente o conceito de Educação Corporativa.

\section{REFERÊNCIAS}

ALBERTIN, Alberto Luiz; BRAUER, Marcus. Resistência à educação a distância na educação corporativa. Revista de Administração Pública, v. 46, n. 5, p.1367-1389, out., 2012. FapUNIFESP (SciELO). DOI: 10.1590/s0034-76122012000500009.

\section{ANDRADE, Patrícia Roberta Paes de. Educação Profissional Na Administração}

Pública: desenvolvendo competências para atender às demandas da sociedade brasileira. 2012. 207 f. Dissertação (Mestrado em Administração Pública), Escola Brasileira de Administração Pública e de Empresas da Fundação Getúlio Vargas, Rio de Janeiro, 2012. Disponível em:

<https://bibliotecadigital.fgv.br/dspace/bitstream/handle/10438/10555/Dissertacao_mest rado_Patricia_Andrade_versao_final_completa\%5B1\%5D.pdf $>$. Acesso em: 13 set. 2017.

ARAUJO, Antônio de Pádua. Competências profissionais e educação corporativa em gestão de pessoas: um estudo empírico. 2011. 323 f. Tese (Doutorado em Administração, Departamento de Administração), Faculdade de Economia, Administração e Contabilidade da Universidade de São Paulo, São Paulo, 2011. Disponível em: <http://www.teses.usp.br/teses/disponiveis/12/12139/tde-08112011171316/pt-br.php>. Acesso em: 12 set. 2017.

BAPTISTA, Sofia Galvão. A inclusão digital: programas governamentais e o profissional da informação - reflexões. Inclusão Social, Brasília, v. 1, n. 2, p. 23-30, abr. 2006. Disponível em: <http://revista.ibict.br/inclusao/article/view/1515/1714>. Acesso em: 13 set. 2017. 
BRASIL. TRIBUNAL DE CONTAS DA UNIÃO. Política pública de inclusão digital. 2015. SeinfraAeroTelecom. Disponível em:

<https://portal.tcu.gov.br/biblioteca-digital/politica-publica-de-inclusao-digital.htm>. Acesso em: 27 set. 2017.

BRASIL. Educação Corporativa. Ministério da Indústria, Comércio Exterior e Serviços. Disponível em: <http://www.mdic.gov.br/legislacao/9-assuntos/categcomercio-exterior/602-educacao-corporativa>. Acesso em: 10 set. 2017.

CARNEIRO, Gracione Batista.; SILVA, Jonathas Luiz Carvalho. Políticas públicas de inclusão digital no contexto da educação escolar como fator de acesso a informação. 2012. Disponível em:

<http://portaldeperiodicos.eci.ufmg.br/index.php/moci/article/viewFile/2176/1350>. Acesso em: 29 set. 2017.

CUNHA, Maria Alexandra Viegas Cortez da.; MIRANDA, Paulo Roberto de Mello. O uso de TIC pelos governos: uma proposta de agenda de pesquisa a partir da produção acadêmica e da prática nacional. Organ. Soc., Salvador, v. 20, n. 66, p. 543-566, set., 2013.

SANTOS CRUZ, José Anderson.; BIZELLI, José Luiz. Sociedade, Tecnologias e Educação: as Tecnologias da Informação e Comunicação e o pensar da sociedade concreta. Cadernos de Educação, Tecnologia e Sociedade, v. 5, p. 258-266, 29 abr., 2014. Science and Education Research Council (COPEC). DOI: 10.14571/cets.v5.258266.

SANTOS CRUZ, José Anderson et al. A utilização do e-learning como ferramenta na educação corporativa. Anais... Congresso Brasileiro de Ciências da Comunicação, 40., 2017, Curitiba. Curitiba: Intercom, 2017. p. 1-10. Disponível em: <http://portalintercom.org.br/anais/nacional2017/resumos/R12-0137-1.pdf>. Acesso em: 10 set. 2017.

\section{EBOLI, Marisa. Educação corporativa e desenvolvimento de competências.}

Disponível em:

<https://edisciplinas.usp.br/pluginfile.php/1846119/mod_resource/content/1/Aula\%201

$0 \% 20-$

$\% 20$ Educa $\%$ C $3 \%$ A7\%C3\%A3o\%20corporativa\%20e\%20desenvolvimento $\% 20 \mathrm{de} \% 20 \mathrm{c}$ ompet\%C3\%AAncias\%20-\%20EBOLI\%2C\%20Marisa.pdf>. Acesso em: 10 ago. 2017.

EBOLI, Marisa. Educação corporativa no Brasil: evolução, conceitos e papéis. In: CASARINI, Fabiana Gradela.; BAUMGARTNER, Marcos (Org.). Educação Corporativa: da teoria à prática. São Paulo: Senac São Paulo, 2012. p. $27-42$.

EBOLI, Marisa. Educação Corporativa no Brasil: da prática à teoria. Disponível em: <http://www.anpad.org.br/admin/pdf/enanpad2004-grt-1816.pdf>. Acesso em: 10 jul. 2017.

EBOLI, Marisa. Fundamentos, princípios e práticas da educação corporativa. In: EBOLI, Marisa (Org.). Educação Corporativa: muitos olhares. São Paulo: Atlas, 2014. p. 14-27. 
RICARDO, Eleonora Jorge. Educação corporativa e aprendizagem: as práticas pedagógicas na era do conhecimento. Rio de Janeiro: Qualitymark, 2012. 120 p.

SÁ, Eliana Maria de Oliveira.; COSTA, Cleide Jane de Sá Araújo. Aplicação de recursos das tecnologias da informação e comunicação na educação corporativa. Ledapeci, Ano III, v. 8, n. 8, ago., 2011.

\section{Como referenciar este artigo}

GUEDES, Elieti Cadamuro.; TOMASI CRUZ, Julio Cesar. Educação Corporativa e Inclusão Digital no contexto da Administração Pública. Revista on line de Política e Gestão Educacional, Araraquara, v.21, n. esp.3, p. 1736-1748, dez. 2017. EISSN:1519-9029. DOI: 10.22633/ rpge.v21.n.esp3.2017.11603

Submetido em: 30/09/2017

Aprovado em: 25/11/2017 